Article

\title{
A Performance Review of Reflectance Based Algorithms for Predicting Phycocyanin Concentrations in Inland Waters
}

\author{
Igor Ogashawara ${ }^{1, *}$, Deepak R. Mishra ${ }^{2}$, Sachidananda Mishra ${ }^{3}$, Marcelo P. Curtarelli ${ }^{1}$ \\ and José L. Stech ${ }^{1}$
}

1 Remote Sensing Division, National Institute for Space Research, Avenida dos Astronautas, 1758, São José dos Campos, SP 12227-010, Brazil; E-Mails: mpedroso@dsr.inpe.br (M.P.C.); stech@dsr.inpe.br (J.L.S.)

2 Department of Geography, University of Georgia, 210 Field Street, Athens, GA 30602,USA; E-Mail: dmishra@uga.edu

3 Dow Agrosciences, 9330 Zionsville Road, Indianapolis, IN 46268, USA;

E-Mail:sm1287@msstate.edu

* Author to whom correspondence should be addressed; E-Mail: igoroga@gmail.com; Tel.: +55-123-208-6484; Fax: +55-123-208-6488.

Received: 26 July 2013; in revised form: 23 September 2013 / Accepted: 23 September 2013 / Published: 26 September 2013

\begin{abstract}
We evaluated the accuracy and sensitivity of six previously published reflectance based algorithms to retrieve Phycocyanin (PC) concentration in inland waters. We used field radiometric and pigment data obtained from two study sites located in the United States and Brazil. All the algorithms targeted the PC absorption feature observed in the water reflectance spectra between 600 and $625 \mathrm{~nm}$. We evaluated the influence of chlorophyll- $a(\operatorname{chl}-a)$ absorption on the performance of these algorithms in two contrasting environments with very low and very high cyanobacteria content. All algorithms performed well in low to moderate PC concentrations and showed signs of saturation or decreased sensitivity for high PC concentration with a nonlinear trend. MM09 was found to be the most accurate algorithm overall with a RMSE of $15.675 \%$. We also evaluated the use of these algorithms with the simulated spectral bands of two hyperspectral space borne sensors including Hyperion and Compact High-Resolution Imaging Spectrometer (CHRIS) and a hyperspectral air borne sensor, Hyperspectral Infrared Imager (HyspIRI). Results showed that the sensitivity for chl- $a$ of PC retrieval algorithms for Hyperion simulated data were less noticable than using the spectral bands of CHRIS; HyspIRI results show that SC00 could be used for this sensor with low chl- $a$ influence. This review of reflectance
\end{abstract}


based algorithms can be used to select the optimal approach in studies involving cyanobacteria monitoring through optical remote sensing techniques.

Keywords: cyanobacteria; phycocyanin; chlorophyll- $a$; band ratio; remote sensing reflectance; hyperspectral sensors

\section{Introduction}

Cyanobacteria commonly known as blue-green (BG) algae are an important phytoplankton class [1] and have received increasing attention because of their occurrence in inland eutrophic waters around the world [2]. The abundant growth of cyanobacteria in aquatic systems creates problems for water resource managers and policy makers due to their capacity to produce toxins also known as "cyanotoxins", which are a major concern for human health [3,4]. Some of the genera of these BG algae produce toxins which cause hepatotoxic, neurotoxic and dermatotoxic effects and general inhibition of protein synthesis in animals and humans [3]. One of the first cases of human fatalities associated with cyanobacteria and their toxins occurred in 1996 at Caruaru, PE, Brazil, where exposure through renal dialysis led to the death of approximately fifty patients [4]. Besides their toxic characteristic, Cyanobacterial Harmful Algal Blooms (CHABs) also degrade aquatic habitats due to their malodorousness [3,5] and the appearance of a scum layer or thick mat on the surface of water.

Tropical aquatic systems such as Brazilian reservoirs are some of the most suitable places where BG algae can multiply very rapidly. It is because the temperature range $\left(25-35^{\circ} \mathrm{C}\right)$ required to achieve BG algae maximal specific rates of growth matches with the average temperature of these aquatic systems [6]. Several BG algae have confirmed their apparent high carbon affinities since they could maintain slow net growth even at $\mathrm{pH}>10$ [7]. Light and nutrient availability are also characteristics which promote CHABs [5]. These facts enhance the importance of monitoring BG algae presence in water supply and recreational reservoirs. However, traditional monitoring methods consist of collection of field samples, laboratory analysis, and manual cell counts. These methods are time-consuming, labor intensive and costly [8]. Efficient alternative methods should be developed in order to improve the monitoring of CHABs and remote sensing has been proved as a valuable tool for this application [9].

For remote sensing techniques, phycocyanin (PC) which is a characteristic photosynthetic pigment in inland $\mathrm{BG}$ algae, has been used as a proxy due to its distinct optical characteristic (absorption peak at $\sim 620 \mathrm{~nm}$ ) [5,10-12]. Initially, cyanobacterial biomass was estimated mostly from chlorophyll- $a$ (chl- $a$ ) concentration since it is the primary and dominant photosynthetic pigment in BG algae [13]. However, recent studies have documented that chl- $a$ is not an accurate estimator of cyanobacterial biomass since it is common to almost all phytoplankton groups [14]. Therefore, recent studies have evaluated the utility of $\mathrm{PC}$ to estimate BG algae abundance, particularly when BG algae are associated with other non-harmful phytoplankton groups [15]. Most of the researchers have been exploiting the PC absorption feature between 615 and $630 \mathrm{~nm}$ to develop empirical and semi-analytical models to detect presence of BG algae in water bodies. However, Mishra et al. [5] proposed the use of a band at $600 \mathrm{~nm}$ since it has less influence of chl- $a$ absorption when compared to $620 \mathrm{~nm}$ and it also has a significant absorption component by PC. 
Thus far, five different algorithms have been proposed for the quantification of BG by exploiting the PC absorption feature: a semi-empirical baseline algorithm (DE93) [16], a single reflectance band ratio algorithm (SC00) [17], a nested semi-empirical band ratio algorithm (SI05) [10], a new single reflectance band ratio algorithm (MI09) [5] and a three band algorithm (HU10) [11]. The baseline algorithm [16] adds reflectance at two wavelengths (600 and $648 \mathrm{~nm})$ to draw a reference baseline, and subtracts the reflectance at $624 \mathrm{~nm}$ which is the absorption maximum of PC. The single reflectance ratio [17] uses a PC fluorescence peak of around $650 \mathrm{~nm}$ and the PC absorption peak around $625 \mathrm{~nm}$. The nested band ratio [10] algorithm was developed for the Medium Resolution Imaging Spectrometer (MERIS) sensor from the European Space Agency (ESA). To match the MERIS band configuration, it uses $620 \mathrm{~nm}$ as the PC absorption maximum and estimates PC concentrations from a semi-analytical inversion procedure using the $620 \mathrm{~nm}$ band. The model also addresses the chl- $a$ influence at the PC absorption band $(620 \mathrm{~nm})$. The new single reflectance ratio [5] uses reflectance at $700 \mathrm{~nm}$ as reference, and targets PC absorption at $600 \mathrm{~nm}$ in order to minimize the chl- $a$ interference. The three band algorithm [11] uses $725 \mathrm{~nm}$ as reference and targets the PC absorption by using the difference in the reflectance at $600 \mathrm{~nm}$ and $615 \mathrm{~nm}$.

All these algorithms were developed for eutrophic waters involving various study sites worldwide with different optical properties. DE93 used coefficients of inherent optical properties in 10 shallow eutrophic lakes in The Netherlands. SC00 dataset was obtained from a hypereutrophic lake, Carter Lake, in Nebraska, USA. SI05 was developed from datasets from two lakes in The Netherlands: Lake Loosdrecht and Lake Ijsselmeer. MI09 was developed in laboratory using two different laboratory cultured cyanobacterial species. HU10 was developed using data from two shallow eutrophic lakes in the United Kingdom. However, all these algorithms were developed for latitudes higher than $35^{\circ}$ and they have not been validated for low latitude areas such as the tropical reservoir in Brazil used in this study. In this research, we have intensively reviewed the performance of the aforementioned algorithms using two unique datasets collected from a tropical reservoir in Brazil and aquaculture ponds in Mississippi, USA. The specific objectives of this research are: (1) to compare and evaluate the performance of the existing reflectance based PC algorithms in two different environmental settings with very high and very low concentrations of chl- $a$ and PC, (2) to apply the existing PC algorithms to a synthetic dataset that was simulated using a Gaussian function as the spectral response function of Hyperion, Compact High-Resolution Imaging Spectrometer (CHRIS) and Hyperspectral Infrared Imager (HyspIRI), and (3) to examine the influence of chl- $a$ on the performance of these algorithms.

\section{Materials and Methods}

\subsection{Study Sites}

We collected field data from two study sites. The first dataset was acquired from the Funil Reservoir located in Itatiaia, RJ, Brazil during 2-5 April 2013, and the second dataset was collected from catfish aquaculture ponds located at the Thad Cochran National Warmwater Aquaculture Center, Stoneville, MS, USA during 13-16 July 2010 and 28-29 April 2011. A summary of study sites, the field campaigns and descriptive statistics of pigments and nutrient concentrations are shown in Table 1. 
Funil Reservoir was constructed during the late 1960s by the damming of the Paraíba do Sul River in Southeast Brazil. This hydrographic basin connects three economically important Brazilian states including Minas Gerais, Rio de Janeiro, and São Paulo. It serves as the primary source of drinking water for domestic supply, irrigation, industrial self-supply systems, aquaculture, and hydroelectric power generation [18]. The reservoir receives waste from one of the main Brazilian industrial areas that has enhanced the eutrophication process in recent decades, consequently causing frequent and intense cyanobacterial blooms [19].

The water for all catfish aquacultures in northwest Mississippi comes from wells pumping the Mississippi River Alluvial Aquifer [12]. It is also known that commercial pond culture of channel catfish is practical only in regions with the proper temperature regime-around $25-30^{\circ} \mathrm{C}-$ for reproduction and rapid growth. According to Tucker [20], the region has the appropriate climatic condition, soil type and water supply for a successful pond culture of channel catfish. However, management practice such as addition of excessive nutrients in the form of commercial catfish food causes phytoplankton blooms dominated by cyanobacteria during warm periods.

The datasets collected from the two study sites represent extreme range of chl- $a$ and PC concentrations and are suitable for performance evaluations of the PC algorithms. For example, average PC in Funil Reservoir was found to be $14.52(\mu \mathrm{g} / \mathrm{L})$, whereas the catfish pond average PC reading was $241.51(\mu \mathrm{g} / \mathrm{L})$ (Table 1). Similar extremes were observed for chl- $a$ as well (Table 1). The observed standard deviation among datasets was helpful in reviewing the performance of the above algorithms at very low and very high concentration ranges and also at a varying chl- $a$ absorption range.

Table 1. Summary statistics for chl- $a$ and phycocyanin (PC) pigment concentrations at study sites.

\begin{tabular}{|c|c|c|c|}
\hline & & Funil Reservoir & Catfish Ponds \\
\hline \multicolumn{2}{|l|}{ Surface Area $\left(\mathrm{km}^{2}\right)$} & 40 & $0.004-0.03$ \\
\hline \multicolumn{2}{|l|}{ Mean depth (m) } & 20 & 1.1 \\
\hline \multicolumn{2}{|c|}{ Time frame of field campaigns (years) } & 2013 & 2010-2011 \\
\hline \multicolumn{2}{|l|}{ Total samples } & 16 & 23 \\
\hline \multirow{5}{*}{ Chl-a $(\mu \mathrm{g} / \mathrm{L})$} & Maximum & 52.78 & 831.35 \\
\hline & Minimum & 4.92 & 59.79 \\
\hline & Range & 47.86 & 771.56 \\
\hline & Average & 19.49 & 230.2 \\
\hline & Standard Deviation & 14.79 & 176.16 \\
\hline \multirow{5}{*}{$\mathrm{PC}(\mu \mathrm{g} / \mathrm{L})$} & Maximum & 35.95 & 857.08 \\
\hline & Minimum & 9.16 & 68.13 \\
\hline & Range & 26.79 & 788.95 \\
\hline & Average & 14.52 & 241.51 \\
\hline & Standard Deviation & 7.70 & 215.72 \\
\hline \multirow{2}{*}{ Total Nitrogen $(\mu \mathrm{g} / \mathrm{L})$} & Maximum & 1,620 & $8,000[12]$ \\
\hline & Minimum & 100 & $4,000[12]$ \\
\hline \multirow{2}{*}{ Total Phosphorus $(\mu \mathrm{g} / \mathrm{L})$} & Maximum & 37.77 & $500[12]$ \\
\hline & Minimum & 16.46 & $800[12]$ \\
\hline
\end{tabular}




\subsection{Remote Sensing Reflectance}

Field radiometric measurements in the Funil Reservoir, Brazil were acquired during 2-5 April , 2013. Radiance and irradiance measurements were carried out using the RAMSES hyperspectral radiometers (TriOS GmbH, Oldenburg, Germany). Measurements were acquired in the visible and near-infrared range of the spectrum (360-900 nm) with $3.3 \mathrm{~nm}$ spectral resolution (0.3 nm accuracy). Six sensors were used, two irradiance and four radiance sensors, acquiring data simultaneously. The two irradiance sensors centered at nominal (excluding effects of wave motion) viewing zenith angle $\left(\theta_{v}\right)$ of $90^{\circ}$ pointed upward (for downwelling irradiance, $E_{d}$ ) and downward (for upwelling irradiance, $E_{u}$ ) directions. A radiance sensor was also pointed downward to measure the upwelling radiance $\left(L_{u}\right)$. These three measures were collected above and below (below the air-water interface, $1 \mathrm{~m}, 2 \mathrm{~m}$ and $3 \mathrm{~m}$ ) the water surface. On the top of the boat, a radiometer with an optical fiber and cosine diffuser (yielding a hemispherical field of view, FOV), pointed upward to acquire the incident spectral irradiance $\left(E_{s}\right)$. The other two radiometers with a $7^{\circ}$ FOV were also on the top of the boat and were centered at nominal $\theta_{v}$ of $40^{\circ}$ in two different directions: upward for the sky radiance $\left(L_{s}\right)$ and downward direction for the radiance received by the sensor pointed at the water surface $\left(L_{w}\right)$.

For the catfish ponds, a dual sensor-system with two inter-calibrated Ocean Optics spectroradiometers (Ocean Optics Inc., Dunedin, FL, USA) were used to acquire remote sensing reflectance $\left(\mathrm{R}_{\mathrm{rs}}\right)$ data in the range $400-900 \mathrm{~nm}$ with a sampling interval of $0.3 \mathrm{~nm}$. The first radiometer was equipped with a $25^{\circ} \mathrm{FOV}$ optical fiber pointed downward to measure the upwelling radiance just below the air-water interface, expressed in digital numbers $\left(D N_{L u(\lambda)}\right)$. The second radiometer was equipped with an optical fiber and cosine diffuser (yielding a $180^{\circ} \mathrm{FOV}$ ), pointed upward to acquire above surface downwelling irradiance, also expressed in digital numbers $\left(D N_{E d(\lambda)}\right)$. The intercalibration of the radiometers was accomplished by measuring the upwelling radiance of a white Spectralon reflectance standard (Labsphere, Inc., North Sutton, NH, USA) simultaneously with incident irradiance. The two radiometers were inter-calibrated immediately before and after measurements in each sampling site.

$\mathrm{R}_{\mathrm{rs}}$ for the optical measures was calculated based on Mobley [21]. For Funil Reservoir, $\mathrm{R}_{\mathrm{rs}}$ was calculated based on Equation 1 and for catfish ponds based on Equation 2.

$$
R_{r s}(\lambda)=\frac{t L_{u}(\lambda)}{n^{2} E_{d}(\lambda)} F_{i}(\lambda)
$$

where, $t$ is the transmittance at the air-water interface (0.98); $n$ is the refractive index of water (1.34); and $F_{i}(\lambda)$ is the spectral immersion coefficient [22].

$$
R_{r s}(\lambda)=\frac{t D N_{L u}(\lambda) D N_{E d, r e f}(\lambda) \rho_{r e f}(\lambda)}{n^{2} D N_{E d}(\lambda) D N_{L u, r e f}(\lambda) \pi} F_{i}(\lambda)
$$

where, $D N_{L u, r e f}$ and $D N_{E d, r e f}$ are digital numbers representing upwelling radiance and downwelling irradiance over the white Spectralon panel; $\rho_{\text {ref }}$ is the irradiance reflectance of the Spectralon panel.

The spectral immersion coefficient for each sensor was derived by following Equation (3) [22].

$$
F_{i}(\lambda)=\frac{n_{w}(\lambda)\left(n_{w}(\lambda)+n_{g}(\lambda)\right)^{2}}{\left(1-n_{g}(\lambda)\right)^{2}}
$$


where, $n_{w}$ is the wavelength-dependent refractive index of freshwater and can be estimated using Equation (4) [23]. $n_{g}$ is the corresponding index of the glass window of the radiance sensor.

$$
n_{w}(\lambda)=1.325147+\frac{6.6096}{\lambda-137.1924}
$$

At both study sites, for each sample point, multiple reflectance measurements were acquired and for which the average spectrum was calculated by using either Equation (1) or (2). The spectra of $R_{\mathrm{rs}}$ were resampled at $1 \mathrm{~nm}$ for further analysis. A synthetic dataset was also created by resampling Rrs measurements matching Hyperion and CHRIS bandwidths using a Gaussian function as the spectral response functions of both sensors.

\subsection{Limnological Parameters}

\subsubsection{Chlorophyll- $a$}

For the Brazilian dataset, water samples were collected from the subsurface, approximately $10 \mathrm{~cm}$ below the water surface, and were kept at cool temperatures until delivery to the laboratory for analysis with the duplicates. The method of chl- $a$ analysis consisted of filtering the collected samples using $\mathrm{GF} / \mathrm{F}$ filters (Whatman, $0.7 \mu \mathrm{m}$ pore size) and then extracting the samples from the filters using $90 \%$ acetone and measuring the absorbance in a Varian Cary 50 Conc UV-VIS spectrophotometer (Agilent Technologies, Santa Clara, CA, USA) [24]. Concentration of chl- $a$ from the spectrophotometric absorbance data was calculated using the equation from Lorenzen [25].

For the North American ponds, the chl- $a$ concentrations were analyzed from the water samples collected in $1 \mathrm{~L}$ Niskin bottles and immediately filtered onto GF/F filters (Whatman, $0.7 \mu \mathrm{m}$ pore size) under low vacuum $(<12.7 \mathrm{~cm}$ of Mercury). Samples were extracted in triplicates using acetone extraction procedure and concentrations were measured using HPLC following the Environmental Protection Agency (EPA) method 447 [26].

\subsubsection{Phycocyanin}

During the Brazilian field campaign in April 2013, an in situ fluorometer called FluoroProbe (bbe Moldeanke, $\mathrm{GmbH}$ ), was used to measure temperature and phytoplankton concentrations. The FluoroProbe data was used to distinguish phytoplankton into four groups: (1) Chlorophyta, (2) PC-rich Cyanobacteria, (3) Diatoms, and (4) Cryptophyta. All data were time stamped and archived on a field handheld personal computer. To measure PC concentration, we used a fluorometer (Turner Designs, model 10-AU-005) with a PC optical kit which uses the excitation and emission wavelengths at $600 \mathrm{~nm}$ and $640 \mathrm{~nm}$, respectively.

During catfish pond field campaigns, water samples were filtered immediately after collection through $0.2 \mu \mathrm{m}$ nucleopore membrane filters (Millipore) under low vacuum. The filters were stored in a $15 \mathrm{~mL}$ falcon tube frozen at $-80{ }^{\circ} \mathrm{C}$ until analysis at the laboratory. For the analysis, filters were transferred to $50 \mathrm{ml}$ polycarbonate centrifuge tubes in order to reach ambient room temperature, and then suspended in $5 \mathrm{~mL}$ of $50 \mathrm{mM}$ phosphate buffer. Samples were homogenized using a sonicator [27] and an ice-bath was used to avoid the destruction of pigments from localized heating. The tip of the 
sonicator was rinsed twice with $5 \mathrm{~mL}$ of $50 \mathrm{mM}$ phosphate buffer each time and the rinse was collected in the centrifuge tube. Samples were centrifuged at $5{ }^{\circ} \mathrm{C}, 27,200 \mathrm{~g}$ for $25 \mathrm{~min}$. This process was repeated one more time using the same settings. The supernatant was collected and absorbance was measured using a Perkin Elmer lambda 850 spectrophotometer (Perkin Elmer Inc., Waltham, MA, USA). Concentration of PC was calculated using the equation from Bennett and Bogorad [28].

\subsection{Model Calibration and Validation}

Three sets of calibration and validations were performed including one on the Funil Reservoir's data, one on the Catfish Pond's data, and the third on a mixed dataset. As the Funil Reservoir and Catfish Pond datasets have significantly different concentration ranges (Table 1), a third dataset was created by mixing the two and then randomly dividing into two datasets, one to be used for calibration $(60 \%)$ and the other for validation (40\%). Models were calibrated using the hyperspectral $\mathrm{R}_{\mathrm{rs}}$ and the formulas listed in Table 2. For each model and each dataset, a linear calibration curve was set between the model values and the PC concentration. We did not use the best fit functions, which were mainly non-linear functions, to avoid an out of range calibration/validation problem because the range of PC concentration in both datasets was extreme without any overlap (Table 1).

Table 2. Summary of $\mathrm{R}_{\mathrm{rs}}$ based bio-optical models used in our study for predicting PC concentration.

\begin{tabular}{|c|c|c|}
\hline Name & Reference & Model \\
\hline DE93 & Dekker [16] & $P C \propto\left[\left(R_{r s}(600)+R_{r s}(648)\right)-R_{r s}(624)\right]$ \\
\hline $\mathrm{SC} 00$ & Schalles \& Yacobi [17] & $P C \propto R_{r s}(650) / R_{r s}(625)$ \\
\hline SI05 & Simis et al. $[10]^{*}$ & $P C \propto R_{r s}(709) / R_{r s}(620)$ \\
\hline MI09 & Mishra et al. [5] & $P C \propto R_{r s}(700) / R_{r s}(600)$ \\
\hline SM12 & Mishra [29] & $P C \propto R_{r s}(709) / R_{r s}(600)$ \\
\hline MM09 & Modified Mishra et al. $[5]^{* *}$ & $P C \propto R_{r s}(724) / R_{r s}(600)$ \\
\hline HU10 & Hunter et al. [11] & $P C \propto\left[\left(R_{r s}^{-1}(615)-R_{r s}^{-1}(600)\right) \cdot R_{r s}(725)\right]$ \\
\hline
\end{tabular}

Notes: * Ratio has been adopted from Simis et al. [10] in their nested semi-analytical algorithm. ** MM09 is the slightly modified version of MM09.

A cross-validation procedure was adopted, if any, by developing linear calibration using one dataset and validating with the two remaining datasets (Table 3). Validations were analyzed by plotting PC Measured versus PC Predicted.

Table 3. Summary of calibration and validation datasets used in the study.

\begin{tabular}{cc}
\hline Calibration & Validation \\
\hline Mixed dataset $(\mathrm{n}=23)$ & Catfish Ponds \\
& Funil Reservoir \\
Funil Reservoir & Catfish Ponds \\
& Mixed dataset $(\mathrm{n}=16)$ \\
\hline \multirow{2}{*}{ Catfish Ponds } & Funil Reservoir \\
& Mixed dataset $(\mathrm{n}=16)$ \\
\hline
\end{tabular}




\subsection{Error Analysis}

Error analysis was performed by comparing measured and predicted PC concentrations. Bias, Mean Square Error (MSE), Mean Absolute Error (MAE), and Root Mean Square Error (RMSE) were used to evaluate model performance and were calculated according to Table 4.

Table 4. Summary of error estimators used in our study.

\begin{tabular}{cc}
\hline Estimator & Formulas \\
\hline Bias & Bias $=\frac{1}{n} \sum_{i=1}^{n}\left(y_{i}-x_{i}\right)$ \\
MAE & $M A E=\frac{1}{n} \sum_{i=1}^{n}\left|y_{i}-x_{i}\right|$ \\
MSE & $M S E=\frac{1}{n} \sum_{i=1}^{n}\left(y_{i}-x_{i}\right)^{2}$ \\
RMSE & $R M S E=\sqrt{M S E}$ \\
\hline
\end{tabular}

Note: where $y_{i}$ and $x_{i}$ are the measured and predicted PC concentration in $i$ th sample.

\subsection{Sensitivity Analysis}

Sensitivity analysis was carried out for the models with the lowest errors and the best validation plots for the simulated data representing the hyperspectral satellite sensors. This analysis was performed to study chl- $a$ interference on the aforementioned PC detection algorithms. The sensitivity analysis was realized using the values derived from PC detection algorithms (Table 2), chl- $a$, and PC concentrations. Surface plots were generated using these three parameters. They were analyzed according to the slope in each axes and the color scale of the surface which represents the PC detection algorithms.

\section{Results and Discussion}

\subsection{Reflectance Characteristics}

The major spectral characteristic features of pigments such as chl- $a$ and PC can be noticed in the $\mathrm{R}_{\mathrm{rs}}$ spectra of Funil Reservoir and catfish ponds (Figure 1). The green peak in water spectra at approximately $550 \mathrm{~nm}$ is commonly due to the scattering from algal cells and relatively low absorption by chl- $a$ [30]. However, in our datasets the green peak is slightly displaced for the two sites, at $560 \mathrm{~nm}$ for catfish ponds and at $570 \mathrm{~nm}$ for the Brazilian reservoir, due to the difference in chl- $a$ concentration range at each site. In aquatic systems with very high chl- $a$ concentrations such as the catfish ponds, the spectra tend to be similar to the spectral response of vegetation. The spectral troughs near $620-625 \mathrm{~nm}$ and 670-675 nm appear because of strong absorption by PC and chl- $a$, respectively [17,31]. The peak at 643-650 $\mathrm{nm}$ appears because of the prominent absorption on both sides at $624 \mathrm{~nm}$ and $670 \mathrm{~nm}$ and also because of the phycocyanin fluorescence maximum of around 640-660 nm [17]. The main difference in the spectral shape between the two study sites occurred at the peak near $700 \mathrm{~nm}$, which appears due to the strong absorption on either side, by chl- $a$ at $670 \mathrm{~nm}$ and by water at $740 \mathrm{~nm}$ [5]. 
However, the magnitudes of the $\mathrm{R}_{\mathrm{rs}}$ at $700 \mathrm{~nm}$ in the catfish ponds data are significantly higher than that that of Funil Reservoir because of the difference in chl- $a$ concentration (Table 1).

Figure 1. $\mathrm{R}_{\mathrm{rs}}$ spectra acquired from Mississippi’s Catfish Ponds (red) and Funil Reservoir (blue).

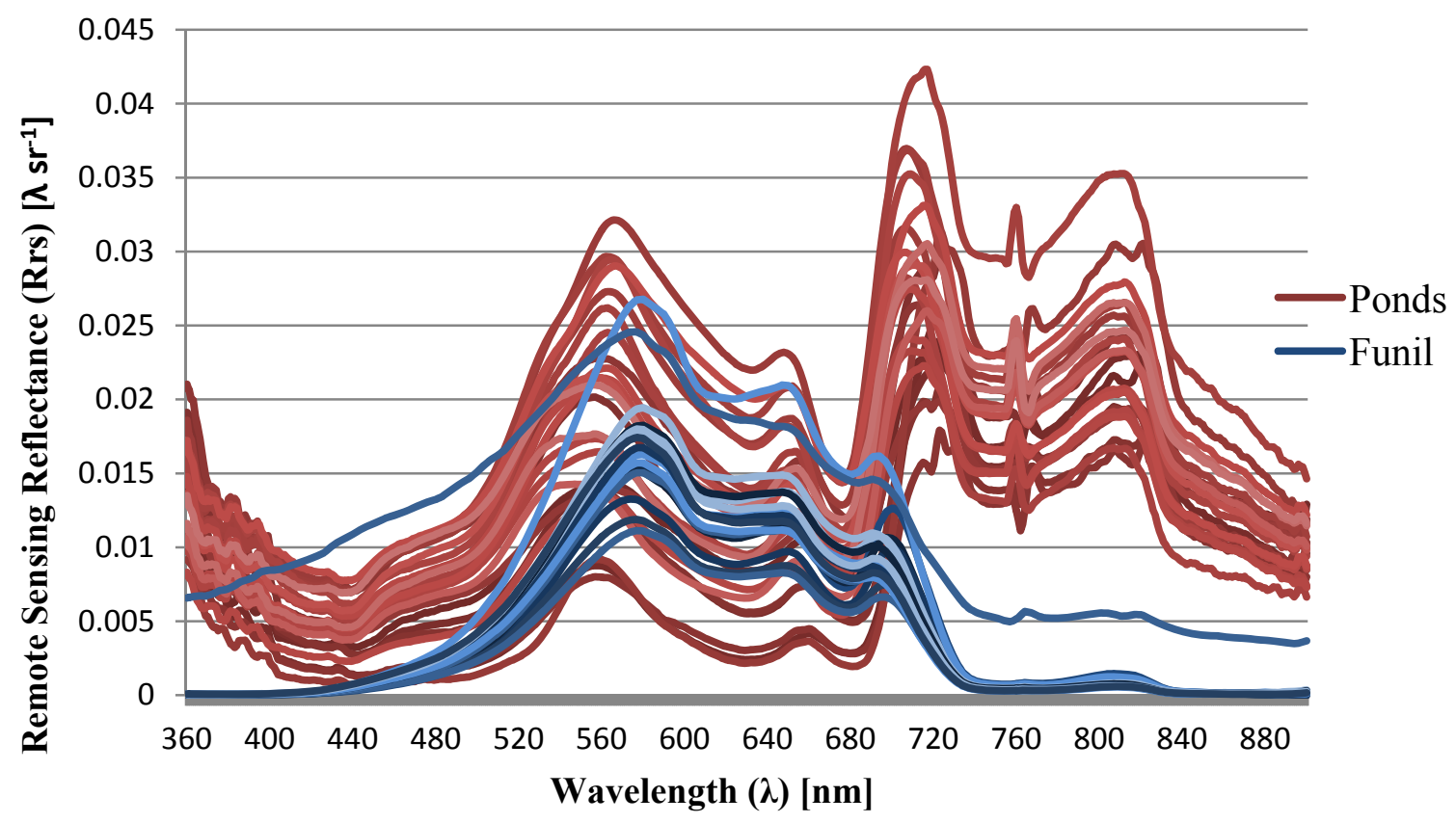

As shown in Table 1, chl- $a$ concentration in Funil Reservoir varied within 4.92-52.78 $\mu \mathrm{g} / \mathrm{L}$, while in the catfish ponds, it was between 59.79 and $1,376.57 \mu \mathrm{g} / \mathrm{L}$. PC:chl- $a$ ratio varied from 0.44 to 1.90 (average $=0.91)$ in Funil site and between 0.30 and 3.28 (average $=1.22$ ) in the catfish ponds. Strong dependency was found between chl- $a$ and PC concentration in both datasets with $\mathrm{R}^{2}$ of 0.89 and 0.84 for Funil Reservoir and catfish ponds, respectively (Figure 2). It corroborates with the fact that the algal community was mostly dominated by cyanobacterial biomass. Species identification was performed using microscopy and the results showed that the most abundant cyanobacteria species at the Funil Reservoir study site was Microcystis aeruginosa and Planktothrix agardhii for the catfish ponds. Microcystis aeruginosa is one of the most common species of cyanobacteria worldwide [31].

Figure 2. Correlation between chl- $a$ and PC concentrations in both study sites.
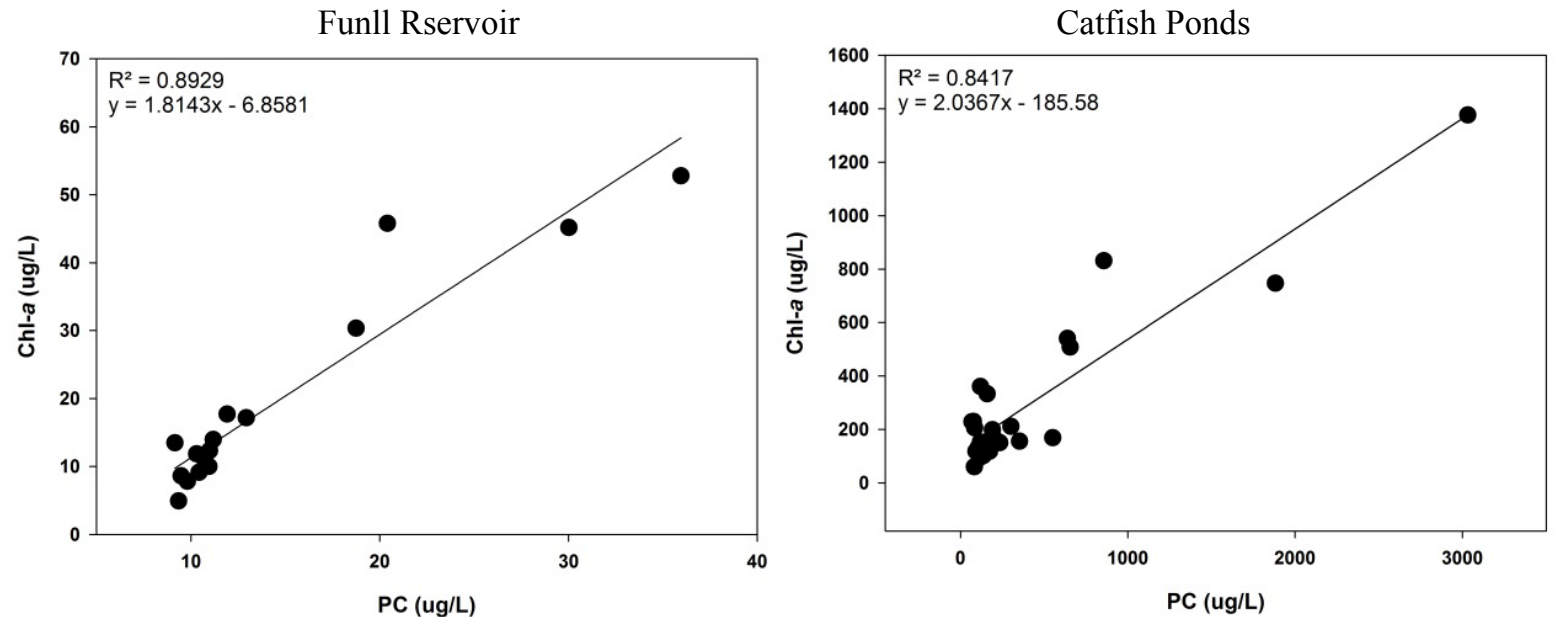


\subsection{Bio-Optical Models}

To analyze the relationship between PC concentrations and several bio-optical models (see Table 2), we used three datasets to calibrate the models. We used a modification of MI09 proposed by Mishra [29] referred to as SM12. SM12 targeted PC absorption at $600 \mathrm{~nm}$ and used the reflectance peak at 709nm. We also proposed a modification of MI09 using the reflectance peak at $724 \mathrm{~nm}$ which is referred to as MM09. All seven models were calibrated using a linear trend between model values and measured PC concentrations. Funil dataset calibration showed the best result with $\mathrm{SM} 12\left(\mathrm{R}^{2}=0.909\right)$. For catfish ponds dataset, the best $R^{2}$ was found with $\operatorname{SI05}\left(R^{2}=0.748\right)$. The mixed dataset showed the lowest $R^{2}$ among all during model calibrations and its best result was found with SI05 $\left(\mathrm{R}^{2}=0.684\right)$ (Table 5). These models presented similar results for the Adjusted $\mathrm{R}^{2}$ confirming consistency in their performance. Calibration analysis also showed the slope (X1) and p-value for each model. DE93 and SC00 showed the highest values for slope in all the datasets. Although HU10 showed low values for its slope in the three datasets, it showed high p-values for Funil (0.179) and Catfish ponds (0.261) datasets. One of the reasons behind the poor calibration results observed for DE93 and HU10 could be the specular reflection from water under wavy conditions that generally gets suppressed in a band ratio algorithm did not get cancelled out due to the band architecture of these two algorithms [30]. The specular reflection occurs mainly due to the wind which generates waves controlling the brightness of most water pixels. Funil Reservoir is more vulnerable to wind compared to catfish ponds and the combinations of single bands used in DE93 and HU10 were not able to suppress the brightness variations due to wave disturbances. Another reason could be the choice of spectral bands used in both algorithms, since DE93 have more influence from the $648 \mathrm{~nm}$ band which is contaminated by chl- $a$ [5] and HU10 is mainly influenced by $724 \mathrm{~nm}$ band which is a chl- $a$ reflectance peak. For accuracy assessment, models were validated by applying the linear regression equations to the other datasets (Figures 3-5). The scatter plots show the estimated PC versus the measured PC concentration. Although some models produced very high $\mathrm{R}^{2}$ during the calibration with one dataset, they did not perform well on other datasets. For example, SM12 which produced the highest $\mathrm{R}^{2}(0.909)$ during calibration, showed that it is not a good estimator for PC concentration during validation. The poor validation results could be due to the difference in the range of PC concentration at two study sites. However, the use of the mixed dataset calibration improved the validation for Funil and catfish datasets (Figures 4 and 5).

Table 5. Coefficients of determination $\left(\mathrm{R}^{2}\right)$ derived from model calibrations using the three datasets for all seven models.

\begin{tabular}{ccccc}
\hline Model & $\mathbf{R}^{\mathbf{2}}$ & Adj. $\mathbf{R}^{\mathbf{2}}$ & X1 & p-value \\
\hline \multicolumn{5}{c}{ Funil Dataset } \\
\hline DE93 & 0.088 & 0.023 & -664.535 & 0.2654 \\
SC00 & 0.745 & 0.727 & 181.122 & $>0.0001$ \\
SI05 & 0.793 & 0.779 & 41.196 & $>0.0001$ \\
MI09 & 0.807 & 0.794 & 50.836 & $>0.0001$ \\
SM12 & 0.909 & 0.902 & 35.638 & $>0.0001$ \\
MM09 & 0.414 & 0.372 & 62.656 & 0.0072 \\
HU10 & 0.125 & 0.062 & -3.841 & 0.1798 \\
\hline
\end{tabular}


Table 5. Cont.

\begin{tabular}{ccccc}
\hline Model & $\mathbf{R}^{\mathbf{2}}$ & Adj. $\mathbf{R}^{\mathbf{2}}$ & $\mathbf{X 1}$ & p-value \\
\hline \multicolumn{5}{c}{ Catfish Ponds Dataset } \\
\hline DE93 & 0.617 & 0.599 & 1381.323 & $>0.0001$ \\
SC00 & 0.338 & 0.306 & 1622.554 & 0.0036 \\
SI05 & 0.748 & 0.736 & 274.873 & $>0.0001$ \\
MI09 & 0.170 & 0.131 & 268.015 & 0.0504 \\
SM12 & 0.591 & 0.572 & 344.990 & $>0.0001$ \\
MM09 & 0.731 & 0.718 & 270.868 & $>0.0001$ \\
HU10 & 0.060 & 0.015 & -12.285 & 0.2611 \\
\hline \multicolumn{5}{c}{ Mixed Dataset } \\
\hline DE93 & 0.051 & 0.006 & 5966.595 & 0.3016 \\
SC00 & 0.518 & 0.495 & 1303.031 & 0.0001 \\
SI05 & 0.684 & 0.669 & 132.365 & $>0.0001$ \\
MI09 & 0.547 & 0.525 & 198.107 & 0.0001 \\
SM12 & 0.640 & 0.623 & 155.970 & $>0.0001$ \\
MM09 & 0.673 & 0.658 & 136.692 & $>0.0001$ \\
HU10 & 0.466 & 0.441 & -13.919 & 0.0003 \\
\hline
\end{tabular}

Validations for the Funil Reservoir dataset used two calibrations: the Mixed and Catfish Ponds calibrations (Figure 4). The mixed dataset calibration showed a poor accuracy for all the models tested. The catfish ponds calibrations also performed very poorly on Funil's dataset; however, HU10 produced the lowest value for the slope and showed a linear behavior. The poor performance of the bio optical models is due to the fact that linear models were chosen for the individual calibrations with Funil and catfish ponds data instead of the best-fit models, which are clearly non-linear mainly at high PC concentrations.

The use of three different datasets showing low, high and mixed ranges of PC concentrations allowed us to analyze which calibration is more accurate for different environments. For a low PC concentration environment, the calibration using HU10 and the mix dataset (wide range) produced the best validation result. For a high PC concentration environment, mix dataset calibrations also produced some of the best results with SI05 and MM09 models due to its wide range. Mixed dataset calibration also showed the best validation plots for the rest of the $40 \%$ of the mixed data using MM09.

However, if we observe the validation plots for the catfish ponds dataset in Figure 5, it is possible to notice a cloud of points in the region of low PC concentration. This cloud of points does not have a linearity which also contributes to the poor validation results. The reason for this non-linear behavior of the scatter plot could be attributed to the dominant species of cyanobacteria in the catfish ponds, the Planktothrix agardhii. Post et al. [32] described that this species can significantly increase the content of chl- $a$, thus varying the irradiance. At sampling points with low PC in the catfish ponds, the PC to chl- $a$ ratio (Table 6) were also lower due to high values of chl- $a$. Thus, the high chl- $a$ concentration for the points with low PC concentration, due to the specific characteristics of Planktothrix agardhii, could have been the reason for the cloud of points and interference in the PC estimation. 
Figure 3. Validation of the models in the mixed dataset using calibrations from (1) Mixed dataset, (2) Funil Reservoir dataset, and (3) Catfish Ponds dataset.

Mixed Dataset
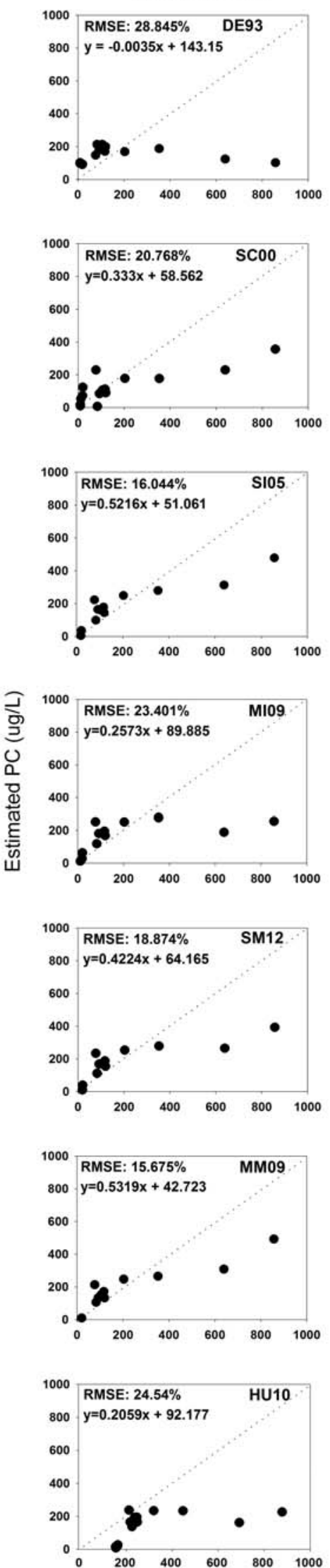

Funil Dataset
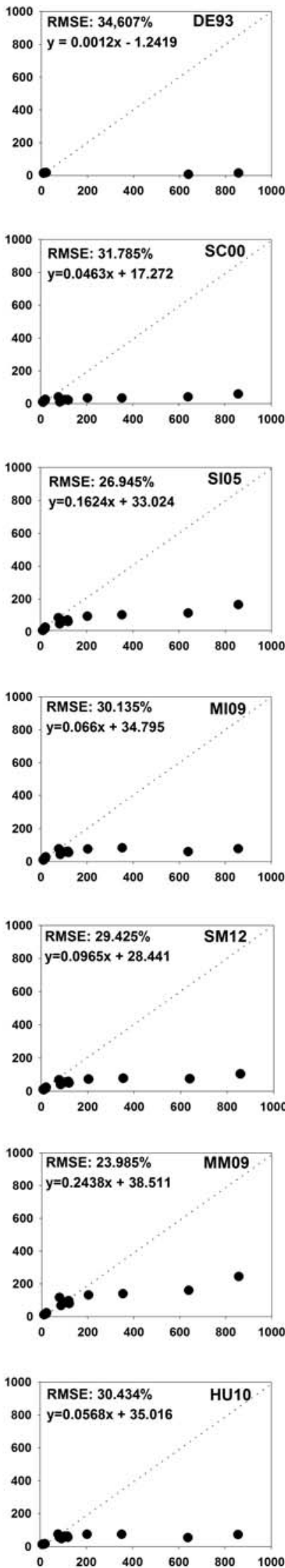

Measured PC (ug/L)
Catfish Ponds Dataset
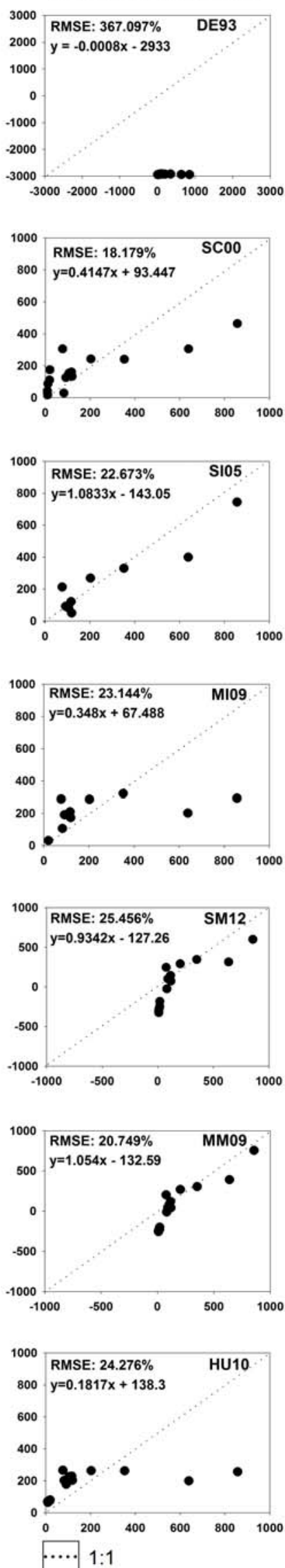
Figure 4. Validation for Funil Reservoir dataset using calibrations from (1) Mixed dataset and (3) Catfish Ponds dataset.
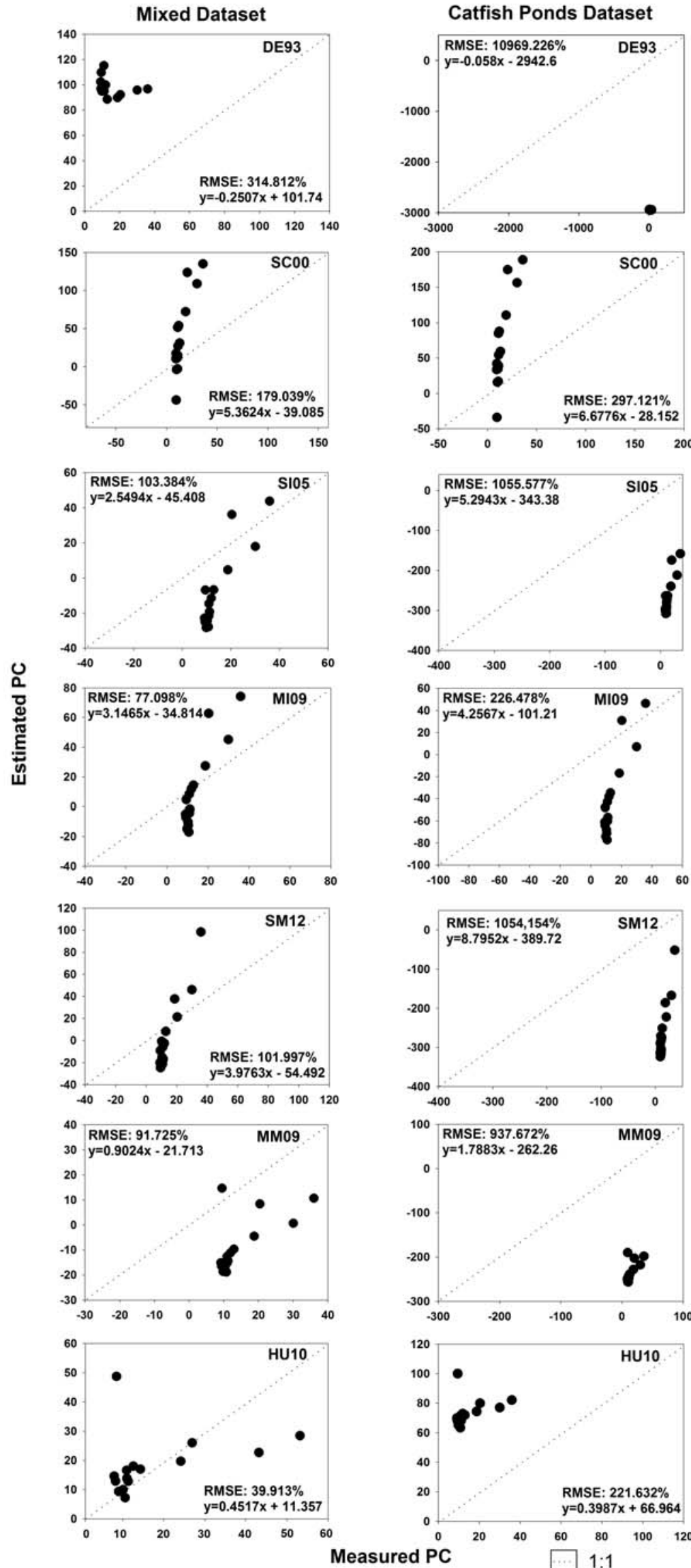
Figure 5. Validation for Catfish Pond dataset using calibrations from (1) Mixed dataset and (2) Funil Reservoir dataset.
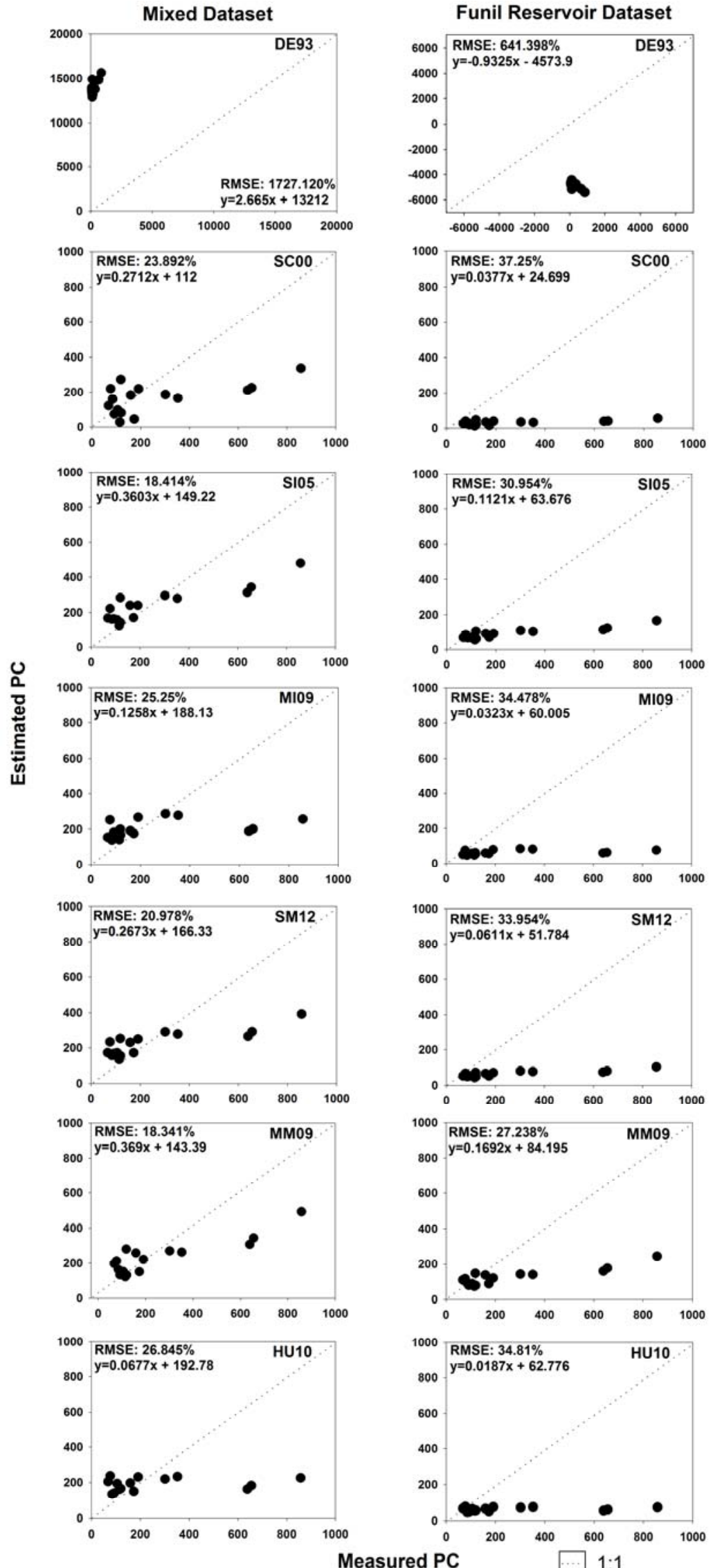
Table 6. PC and Chl- $a$ ratio for the Catfish Ponds dataset.

\begin{tabular}{ccc}
\hline PC & Chl- $\boldsymbol{a}$ & PC:Chl- $\boldsymbol{a}$ \\
\hline 68.13 & 228.26 & 0.30 \\
77.19 & 229.25 & 0.33 \\
83.19 & 59.79 & 1.39 \\
84.88 & 205.60 & 0.41 \\
92.24 & 117.40 & 0.78 \\
105.75 & 131.05 & 0.80 \\
114.50 & 94.03 & 1.22 \\
116.82 & 109.26 & 1.07 \\
118.79 & 360.01 & 0.33 \\
119.02 & 152.50 & 0.78 \\
119.61 & 130.43 & 0.91 \\
136.44 & 101.40 & 1.34 \\
159.31 & 332.38 & 0.48 \\
173.54 & 117.42 & 1.48 \\
191.12 & 198.50 & 0.96 \\
203.17 & 164.30 & 1.23 \\
234.32 & 149.61 & 1.56 \\
301.60 & 210.83 & 1.43 \\
352.66 & 155.54 & 2.26 \\
550.96 & 168.22 & 3.27 \\
639.02 & 539.73 & 1.18 \\
655.33 & 507.70 & 1.29 \\
857.08 & 831.35 & 1.03 \\
\hline
\end{tabular}

Table 7 shows the error analysis for all models and for the three validation datasets. For the mixed dataset, the best results were obtained by using MM09 in the Mixed and Funil's calibrations, with an RMSE of $15.675 \%$ and $23.985 \%$, respectively. The best catfish ponds calibration for the mixed dataset used SC00 algorithm and had a RMSE of $18.179 \%$. The lowest errors in Funil dataset were found using HU10 model with a RMSE of $221.63 \%$ and $40.92 \%$ for catfish ponds and mixed calibrations, respectively. It showed that the errors decreased by the use of mixed calibration, enhancing the importance of using a large range of PC concentrations for the calibration of these models. These results also showed that the catfish ponds' calibration mostly overestimates the PC prediction values. On the other hand, for the catfish ponds dataset, it was observed that the models which were calibrated with low PC range perform better when compared to the opposite (predicting low PC concentration from calibrations with high PC concentration). This could be due to the fact that mostly the nonlinearity or signs of saturation during calibration were observed at high PC concentrations. Overall, results showed that the MM09 was the best model for the Funil and Mixed datasets with a RMSE of $23.985 \%$ and $15.675 \%$, respectively. These results also confirmed that it is possible to improve the accuracy of these models since the validation results (Figures 3-5) showed that there is still some residual interference at the $\mathrm{PC}$ absorption region. The interference was observed for data points where the PC concentration was zero but the bio-optical models produced a significant value. Interference from $\mathrm{CDOM}$ absorption is not an issue for the spectral range used in these models; therefore, the 
residual scattering from algal pigments and TSS are the potential interference factors at these wavelengths.

Table 7. Error analysis for the linear calibrations for each model and dataset (shaded areas represent the lowest errors).

\begin{tabular}{|c|c|c|c|c|c|c|c|}
\hline \multicolumn{8}{|c|}{$\begin{array}{c}\text { Mixed Dataset } \\
\text { Mixed Calibration }\end{array}$} \\
\hline Estimator & D93 & $\mathrm{SCO0}$ & S05 & M09 & SM12 & MM09 & H10 \\
\hline Bias & 27.884 & 55.119 & 30.472 & 36.709 & 34.287 & 36.062 & 43.176 \\
\hline MAE & 156.034 & 100.247 & 84.726 & 111.710 & 95.558 & 79.642 & 111.087 \\
\hline MSE & $59,821.765$ & $31,009.467$ & $18,507.809$ & $39,371.406$ & $25,612.029$ & $17,665.301$ & $43,296.194$ \\
\hline RMSE & 244.585 & 176.095 & 136.043 & 198.422 & 160.038 & 132.911 & 208.077 \\
\hline RMSE(\%) & 28.845 & 20.768 & 16.044 & 23.401 & 18.874 & 15.675 & 24.540 \\
\hline \multicolumn{8}{|c|}{ Funil Reservoir Calibration } \\
\hline Bias & 171.474 & 145.279 & 109.744 & 124.394 & 125.551 & 90.375 & 125.742 \\
\hline MAE & 173.428 & 147.109 & 112.190 & 125.891 & 125.922 & 96.090 & 127.198 \\
\hline MSE & $86,109.276$ & $72,634.933$ & $52,200.685$ & $65,289.794$ & $62,249.894$ & $41,362.024$ & $66,594.099$ \\
\hline RMSE & 293.444 & 269.509 & 228.475 & 255.519 & 249.499 & 203.377 & 258.058 \\
\hline RMSE(\%) & 34.607 & 31.785 & 26.945 & 30.135 & 29.425 & 23.985 & 30.434 \\
\hline \multicolumn{8}{|c|}{ Catfish Ponds Calibration } \\
\hline Bias & $3,103.557$ & 6.313 & 128.852 & 43.635 & 138.474 & 123.386 & 1.175 \\
\hline MAE & $3,103.557$ & 105.260 & 154.526 & 125.628 & 174.409 & 147.100 & 140.362 \\
\hline MSE & $9,688,859.449$ & $23,761.486$ & $36,958.560$ & $38,411.144$ & $46,590.750$ & $30,953.637$ & $42,369.837$ \\
\hline RMSE & $3,112.693$ & 154.148 & 192.246 & 195.988 & 215.849 & 175.936 & 205.839 \\
\hline RMSE(\%) & 367.097 & 18.179 & 22.673 & 23.114 & 25.456 & 20.749 & 24.276 \\
\hline \multicolumn{8}{|c|}{ Funil Reservoir Dataset } \\
\hline \multicolumn{8}{|c|}{ Catfish Ponds Calibration } \\
\hline Bias & $2,939.150$ & -57.184 & 279.993 & 52.170 & 275.038 & 250.650 & -58.610 \\
\hline MAE & $2,939.150$ & 62.948 & 279.993 & 55.642 & 275.038 & 250.650 & 58.610 \\
\hline MSE & $8,638,835.017$ & $6,338.247$ & $79,998.696$ & $3,682.608$ & $79,783.183$ & $63,125.493$ & $3,526.687$ \\
\hline RMSE & $2,939.190$ & 79.613 & 282.840 & 60.684 & 282.459 & 251.248 & 59.386 \\
\hline RMSE(\%) & $10,969.226$ & 297.121 & $1,055.577$ & 226.478 & $1,054.154$ & 937.672 & 221.632 \\
\hline \multicolumn{8}{|c|}{ Mixed Calibration } \\
\hline Bias & -83.570 & -24.276 & 22.903 & 3.636 & 11.262 & 23.130 & -3.393 \\
\hline MAE & 83.570 & 34.342 & 25.841 & 16.831 & 23.490 & 23.768 & 5.927 \\
\hline MSE & $7,115.514$ & $2,301.443$ & 767.377 & 426.762 & 746.925 & 604.059 & 114.377 \\
\hline RMSE & 84.354 & 47.973 & 27.702 & 20.658 & 27.330 & 24.578 & 10.695 \\
\hline RMSE(\%) & 314.812 & 179.039 & 103.384 & 77.098 & 101.997 & 91.725 & 39.913 \\
\hline \multicolumn{8}{|c|}{ Catfish Ponds Dataset } \\
\hline \multicolumn{8}{|c|}{ Funil Reservoir Calibration } \\
\hline Bias & $5,040.604$ & 207.704 & 150.849 & 173.707 & 174.972 & 116.461 & 174.222 \\
\hline MAE & $5,040.604$ & 207.704 & 151.761 & 173.707 & 174.972 & 126.505 & 174.222 \\
\hline MSE & $25,606,599.392$ & $86,365.614$ & $59,637.746$ & $73,992.014$ & $71,760.882$ & $46,177.712$ & $75,424.552$ \\
\hline RMSE & $5,060.296$ & 293.880 & 244.208 & 272.015 & 267.882 & 214.890 & 274.635 \\
\hline RMSE(\%) & 641.398 & 37.250 & 30.954 & 34.478 & 33.954 & 27.238 & 34.810 \\
\hline
\end{tabular}


Table 7. Cont.

\begin{tabular}{cccccccc}
\hline \multicolumn{7}{c}{ Catfish Ponds Dataset } \\
\hline \multicolumn{7}{c}{ Mixed Calibration } \\
\hline Bias & -13613.808 & 64.019 & 5.273 & 22.999 & 10.620 & 8.999 & 32.391 \\
MAE & 13613.808 & 128.858 & 104.186 & 128.950 & 115.237 & 104.689 & 140.536 \\
MSE & $185,669,971.223$ & $35,529.975$ & $21,105.169$ & $39,685.667$ & $27,393.270$ & $20,938.331$ & $44,856.741$ \\
RMSE & $13,626.077$ & 188.494 & 145.276 & 199.213 & 165.509 & 144.701 & 211.794 \\
RMSE(\%) & 1727.120 & 23.892 & 18.414 & 25.250 & 20.978 & 18.341 & 26.845 \\
\hline
\end{tabular}

\subsection{Sensitivity Analysis}

Sensitivity analyses were performed using the mixed dataset due to its overall strong performance and wide PC concentration range. Some of the best performing models including SC00, SI05, MI09 and MM09 were used to analyze their sensitivity to chl- $a$ (Figure 6). The color scale is based on individual model outputs. Figure 6A showed that SC00 was insensitive to both chl- $a$ and PC, and therefore, is not suitable to retrieve PC accurately although it was almost insensitive to chl- $a$. SI05 on the other hand showed (Figure 6B) to be a good estimator for PC concentration because of its high sensitivity to PC. However, it also showed a high sensitivity to chl- $a$ (Figure 6B). In contrast, MI09 showed high sensitivity to PC and low sensitivity to chl- $a$ corroborating with the fact that the chl- $a$ effect on MI09 band ratio is comparatively less than other models as previously shown in Mishra et al. [5] (Figure 6C). MI09 was developed to avoid the residual chl- $a$ absorption at the widely used PC absorption maxima, i.e., at $620 \mathrm{~nm}$. This was accomplished by moving the PC sensitive band to 600 $\mathrm{nm}$ instead of using $620 \mathrm{~nm}$ in the band ratio model. MM09, a modified MI09, showed high sensitivity to both PC and chl- $a$ similar to SIO5 (Figure 6D).

Figure 6. Sensitivity analysis showing the interference of chl- $a$ on the performance of (A) SC00, (B) SI05, (C) MI09, and (D) MM09.
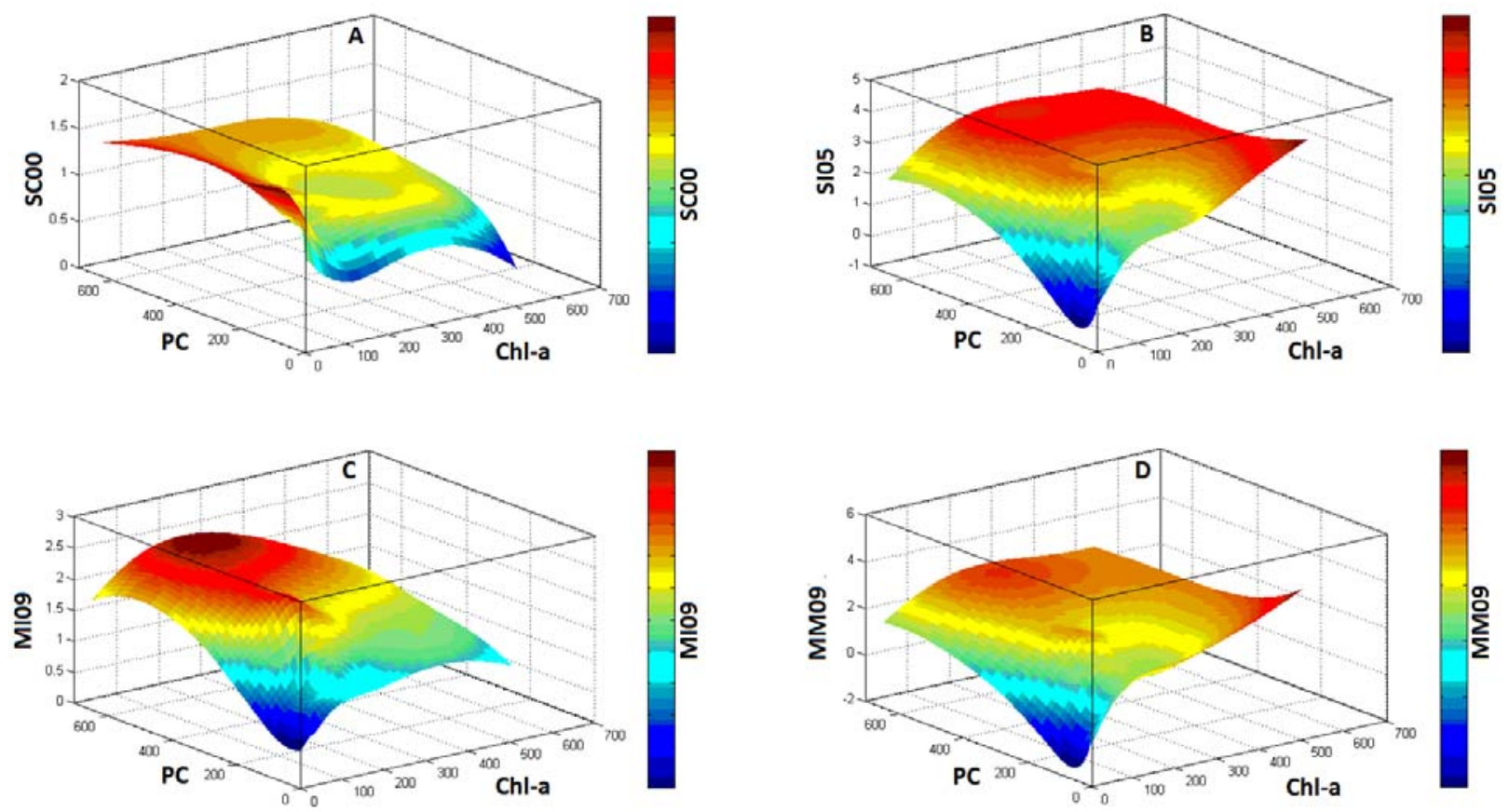
These results showed that, overall, MI09 has the least interference from chl- $a$ and can be used to accurately monitor BG in widely varying water bodies. Although MI09 was developed using a dataset collected from a series of controlled laboratory experiments with two cyanobacteria species (Synechocystis sp. and Anabaena sp.) [5], our review shows that it still serves as the most accurate algorithm to be used in natural environments. To confirm the results of the sensitivity analysis, a linear regression between these models and chl- $a$ concentration was conducted. The results of the regression showed that SC00 and MI09 were the models without a significant dependency on chl- $a$ concentration with $\mathrm{R}^{2}$ of 0.42 and 0.38 , respectively. On the other hand to the contrary, SI05 and MM09 showed a significant dependency on chl- $a$ with a $\mathrm{R}^{2}$ of 0.65 and 0.66 , respectively (results not shown). This analysis also revealed that MI09 can be used in semi-analytical algorithms to solve for PC absorption at $600 \mathrm{~nm}$ which can be safely assigned to PC without chl- $a$ interference.

\subsection{Sensor Analysis}

The increasing demand for monitoring water quality in lakes and reservoirs used for water supply increases the necessity to develop accurate satellite PC products. However, most of the commonly used multispectral satellite sensors do not have the desired PC prediction band at 600 or $620 \mathrm{~nm}$. The absence of specific narrow bands in multispectral sensors to target and highlight specific biophysical and biochemical parameters could be surpassed with hyperspectral sensors [33]. Reflectance products from hyperspectral satellite sensors such as Hyperion and CHRIS onboard Earth Observation 1 (EO-1), Project for On-Board Autonomy (PROBA), and the future sensor HyspIRI, which is being designed using contiguous bands with a spatial resolution of $60 \mathrm{~m}$ and spectral resolution of $10 \mathrm{~nm}$, can be used to develop PC products and map spatial distribution of cyanobacteria in inland and coastal waters. The use of simulated HyspIRI bands for any hyperspectral models provides valuable information for next generation hyperspectral sensors from which users will have to extract appropriate optimal wavebands relevant for their application, or, as an alternative, they could carry specialized optimal sensors with selective wavebands, focusing on gathering data for targeted applications [34]. Therefore, we simulated Hyperion, CHRIS and HyspIRI spectral bands by using a Gaussian spectral response function on the field $\mathrm{R}_{\mathrm{rs}}$ data [34-36]. For the Hyperion spectral bandwidth simulation, we used the bands centered at: 599.8, $609.97,620.15,650.67,701.55,711.72$ and $721.9 \mathrm{~nm}$. For CHRIS bandwidth simulation, we used the spectral bands centered at: 603, 613, 622, 651, 703, 709, 722 and $728 \mathrm{~nm}$. For HyspIRI bandwidth simulation we used the spectral bands centered at: 605, 615, 625, 655, 705 and $725 \mathrm{~nm}$. These bands were used to develop SC00, SI05, MI09 and MM09 models and used their mixed calibrations.

Results from the linear calibration/validation analysis for the Hyperion, CHRIS and HyspIRI spectral bands are presented in Table 8 . Among all models, SI05 performed best by producing highest $\mathrm{R}^{2}$ and lowest RMSE in calibration and validation for the Hyperion bands (Table 8). However, the models using CHRIS bands have a better linear calibration with a maximum $\mathrm{R}^{2}$ of 0.72 using SI05 and lower RMSE of $14.45 \%$. The performance of SI05 on the HyspIRI data was also better than the others with a $\mathrm{R}^{2}$ of 0.71 and a RMSE of $14.87 \%$.

The sensitivity analysis for Hyperion bands (Figure 7) revealed a similar behavior as shown by the hyperspectral models (Figure 6). For example, Figure 7A also shows that although SC00 was insensitive to chl- $a$, it was not a good predictor of PC concentration. MI09 showed to be most sensitive 
to PC and the least sensitive to chl- $a$ (Figure 7C). SI05 and MM09 performed similarly by showing sensitivity to both PC and chl-a. (Figure 7B, D). Overall, we noticed during sensitivity analysis that although SI05 and MM09 sometimes produced the highest $\mathrm{R}^{2}$ and lowest RMSE during calibration and validation, their dependency on chl- $a$ is consistently greater than MI09. Therefore, sometimes they also act as a strong predictor of chl- $a$ concentration.

Table 8. Error analysis for linear calibrations for Hyperion and CHRIS bands.

\begin{tabular}{ccccccc}
\hline & \multicolumn{2}{c}{ Hyperion } & \multicolumn{2}{c}{ CHRIS } & \multicolumn{2}{c}{ HyspIRI } \\
\hline & $\mathbf{R}^{\mathbf{2}}$ & RMSE (\%) & $\mathbf{R}^{\mathbf{2}}$ & RMSE (\%) & $\mathbf{R}^{\mathbf{2}}$ & RMSE (\%) \\
SC00 & 0.42 & 23.23 & 0.49 & 16.81 & 0.54 & 18.38 \\
SI05 & 0.69 & 15.54 & 0.72 & 14.45 & 0.71 & 14.87 \\
M109 & 0.55 & 22.63 & 0.64 & 18.43 & 0.62 & 20.16 \\
MM09 & 0.68 & 16.30 & 0.68 & 15.41 & 0.68 & 15.58 \\
\hline
\end{tabular}

Figure 7. Models using simulated Hyperion data: sensitivity analysis showing the interference of chl- $a$ on the performance of (A) SC00, (B) SI05, (C) MI09, and (D) MM09.
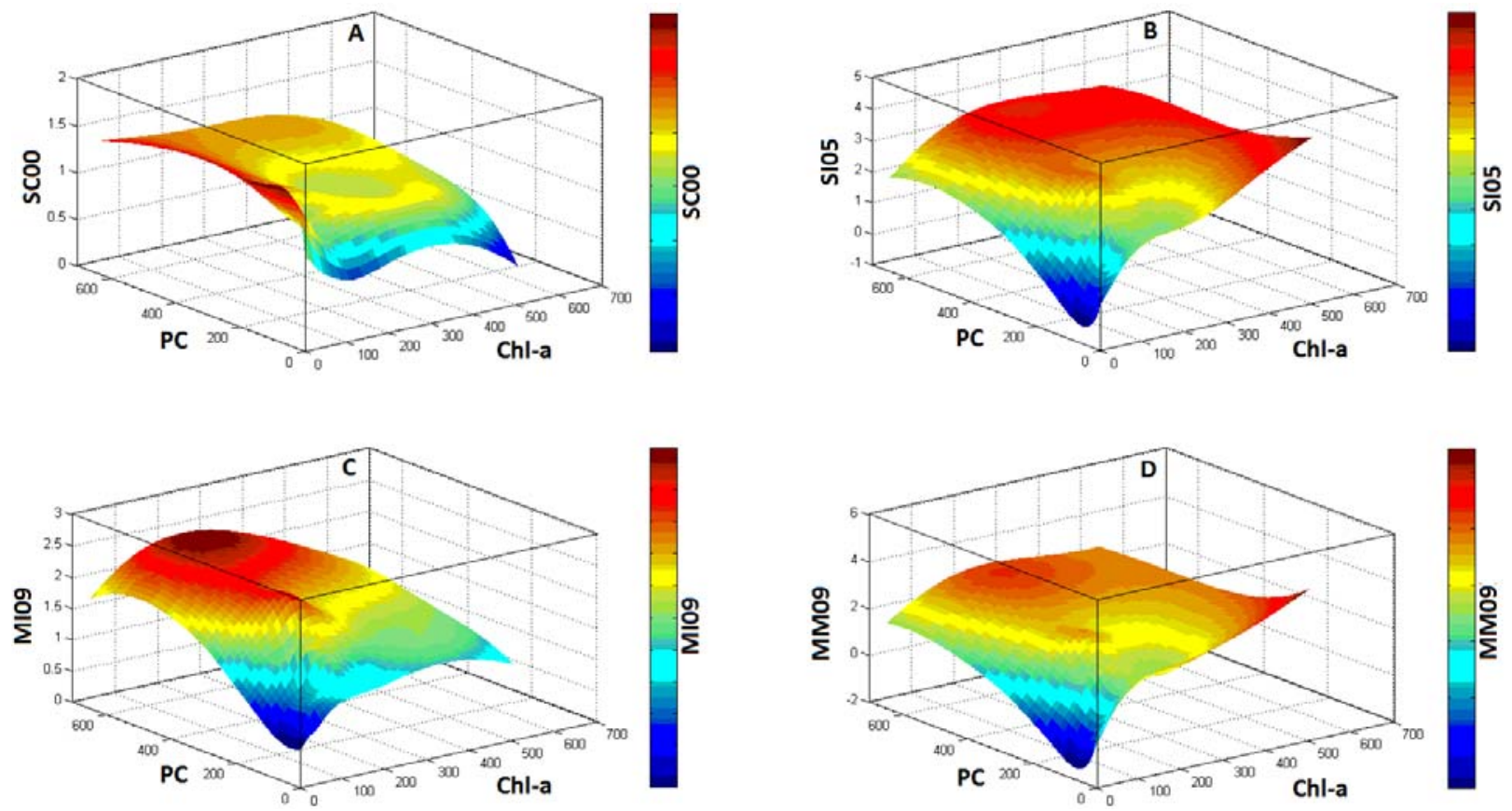

The difference in performance of Hyperion and CHRIS sensors could be attributed to the variable bandwidth of these sensors. Although data for both sensors were simulated using the Gaussian response function, the bandwidths were different. Hyperion bandwidths vary from 10.5 to $10.69 \mathrm{~nm}$ while CHRIS bandwidths vary from 6 to $12 \mathrm{~nm}$. CHRIS has wider bandwidths near the PC absorption maxima and narrower bandwidths near the chl- $a$ reflectance peak, while Hyperion bands have almost the same width in those areas. This difference can explain the models sensitivity to chl- $a$ concentration, since the narrow bands enhance the spectral response in the chl- $a$ reflectance peak.

The sensitivity analysis for CHRIS dataset (Figure 8) revealed that all four models are sensitive to variations in PC concentration. However, all models showed to be more sensitive to the presence of chl- $a$, having high values when the chl- $a$ was also higher and low values when the chl- $a$ was low. 
Figure 8. Models using simulated CHRIS data: sensitivity analysis showing the interference of chl- $a$ on the performance of (A) SC00, (B) SI05, (C) MI09, and (D) MM09.
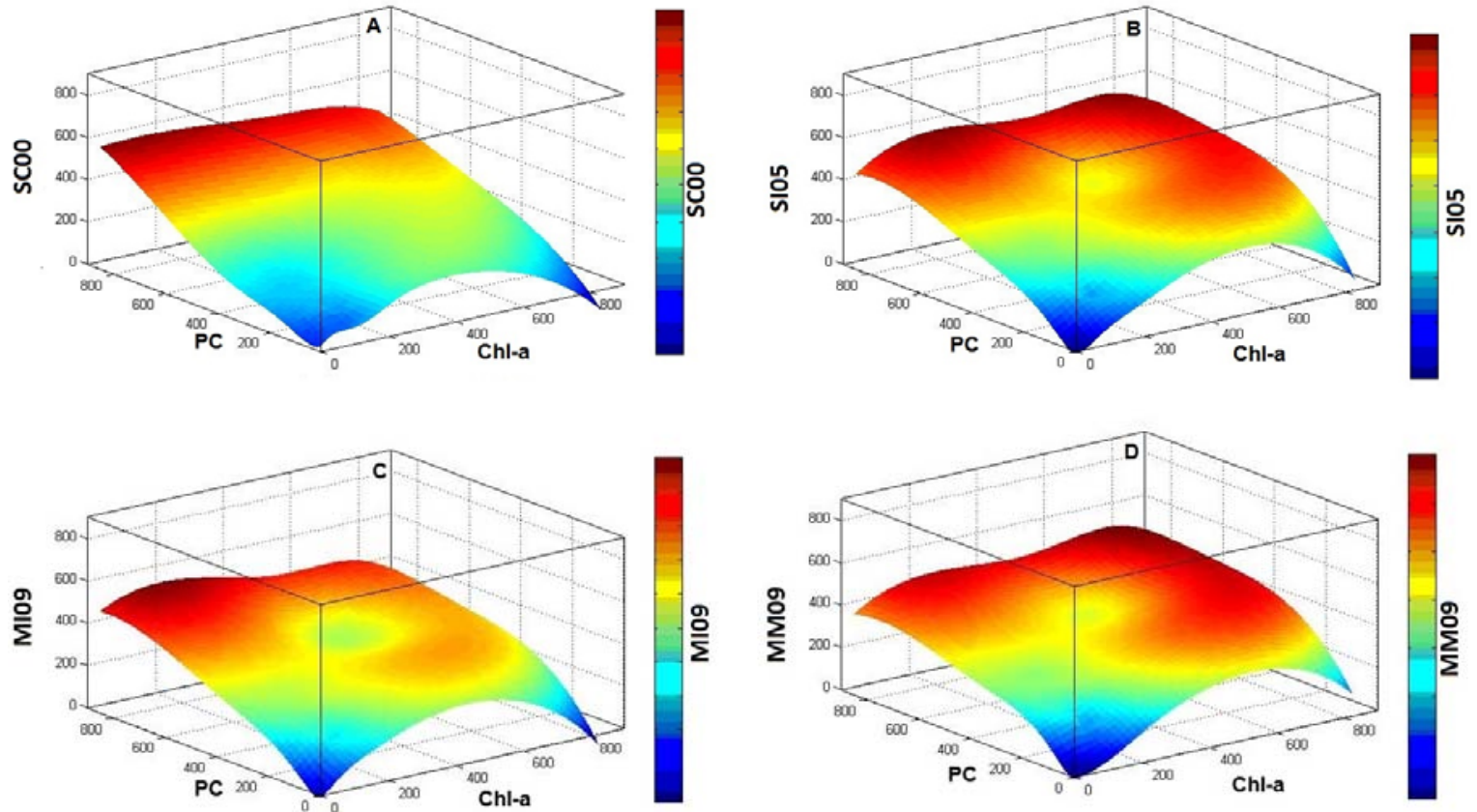

The sensitivity analysis for HyspIRI dataset (Figure 9) revealed a good sensitivity of SC00 to PC concentration. MI09 and SI05 showed a moderate sensitivity to PC concentration. However, SI05 and MM09 appeared to be more sensitive to the presence of chl-a, having high values when the chl- $a$ concentration was higher and vice versa. On the other hand, SC00 and MI09 showed no sensitivity to chl- $a$ presence. For HyspIRI, the best sensitivity performance was found in SC00, since it appeared to be sensitive to variations in PC concentration and also showed no sensitivity to chl- $a$ presence

Figure 9. Models using simulated HyspIRI data: sensitivity analysis showing the interference of chl- $a$ on the performance of (A) SC00, (B) SI05, (C) MI09, and (D) MM09.
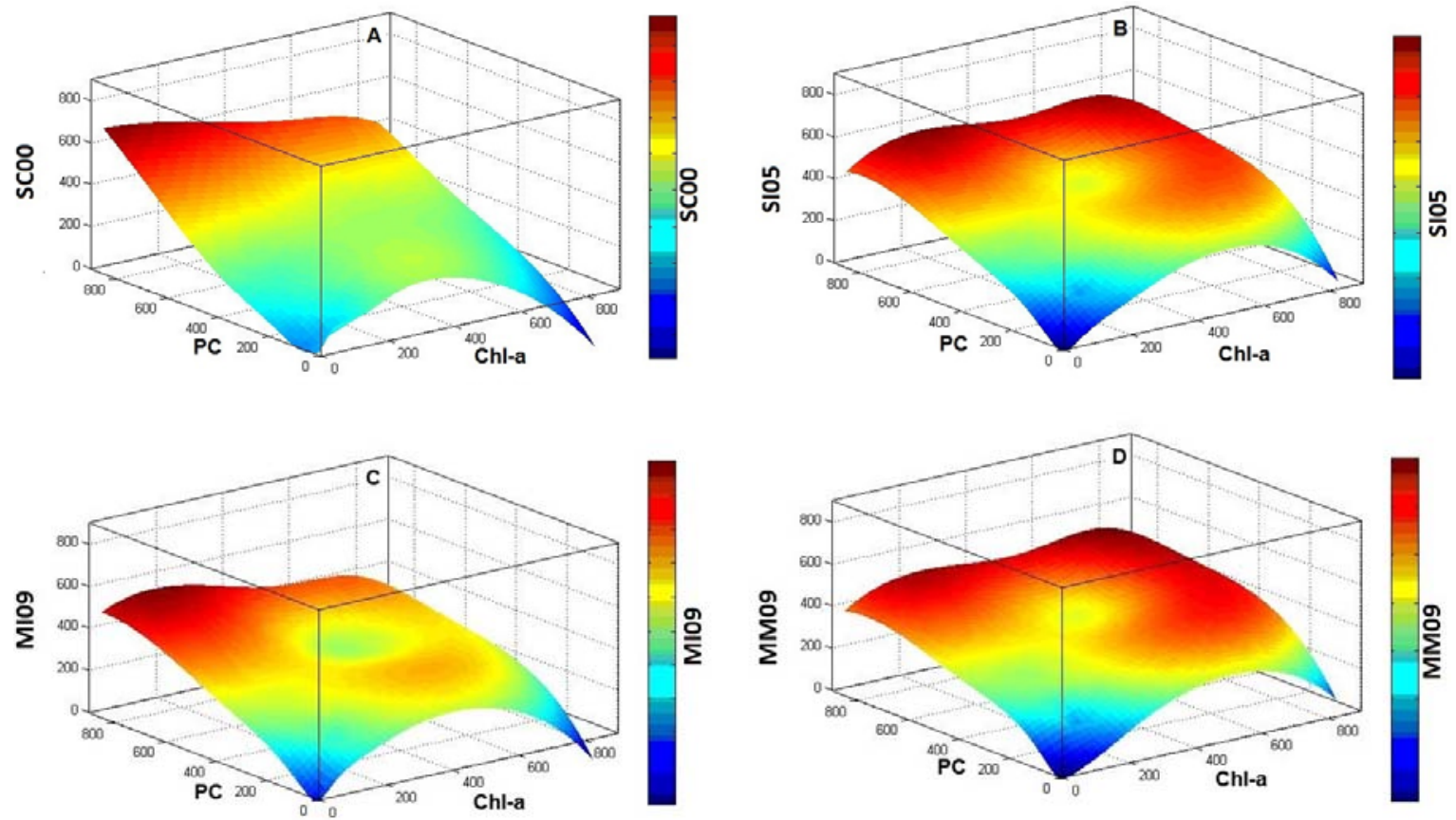
As the sensor bands confirm the algorithms input requirements, accurate atmospheric correction are required in order to avoid errors in the estimation of PC. In this research, we used proximal remote sensing measurements which do not require atmospheric correction. Therefore, applying these algorithms as described may not work for orbital sensors without an accurate atmospheric correction. However, Kutser [37] showed that the standard atmospheric correction procedures fail for water bodies with dense BG blooms since they operate under the assumption that water-leaving radiance at NIR is almost zero; but in case of a water body with dense algal bloom, that assumption is not accurate and the NIR signal cannot be ignored.

\section{Conclusions}

In this paper, we have reviewed and discussed the performance of all available reflectance based algorithms to predict phycocyanin (PC) content in waters with wide ranges of pigment concentration. All PC algorithms analyzed in this paper used different wavelength regions in the reflectance spectra including an absorption peak of around $600-620 \mathrm{~nm}$, a fluorescence peak of around $650 \mathrm{~nm}$, and a chl- $a$ reflectance peak between 700 and $724 \mathrm{~nm}$. We applied seven reflectance based bio-optical algorithms including Dekker [16], Schalles \& Yacobi [17], Simis et al. [10], Mishra et al. [5], Mishra [29], Modified Mishra et al. [5], and Hunter et al. [11] (Table 2) for calibration and validation using three datasets that contained observations from two study sites (Catfish Ponds, MS, USA and Funil Reservoir, RJ, Brazil). Overall, we conclude that the use of chl- $a$ reflectance peak near $700 \mathrm{~nm}$ and PC absorption at $600 \mathrm{~nm}$ is the best combination to be used in a PC prediction algorithm The Dekker [16] algorithm showed the highest RMSE for all the datasets. Its best performance occurred in the mixed dataset (RMSE of $28.845 \%$ ) where it showed a linear relationship at low PC concentrations, however, at very high PC concentration, this relationship was no longer linear. The relatively high errors produced by the Dekker [16] algorithm in the three datasets suggest that an empirical parameterization in the calibration dataset could improve its performance. The Schalles \& Yacobi [17] algorithm showed its best performance in the high PC concentrations datasets, probably because it was developed using optical data obtained in eutrophic, cyanobacteria-dominated lakes [17].

However, the use of the $650 \mathrm{~nm}$ band contaminates this model with strong interference from chl- $a$, thus decreasing its PC prediction capacity. Similarly, Simis et al. [10] showed the lowest error values for the high PC dataset, and for the low PC dataset, it did not have the same accuracy. In our datasets, chl- $a$ concentration was high for the data points with low PC (i.e., PC:chl- $a$ ratio was low for low PC points) and therefore, interference of chl- $a$ at $620 \mathrm{~nm}$ for low PC points was higher and affected the accuracy of the algorithm by Simis et al. [10]. Mishra et al. [5] showed the highest accuracy among all models and the least interference from chl- $a$ because of the use of a band at $600 \mathrm{~nm}$, and by moving away from the PC absorption maxima at $620 \mathrm{~nm}$. Its derivatives, Mishra [29] and Modified Mishra et al. [5], used bands at 709 and $724 \mathrm{~nm}$ instead of at 700 and they produced mixed results with a higher sensitivity to chl-a compared to Mishra et al. [5]. Hunter et al. [11] showed the lowest \%RMSE for the low PC data points. However, for the high PC data points, it produced high errors due to the use of two bands (600 and $615 \mathrm{~nm}$ ) in the $\mathrm{PC}$ absorption region.

Overall, the sensitivity analyses were crucial in determining the efficiency of each algorithm, since it was possible to observe the interference of chl- $a$ in these algorithms. Mishra et al. [5] appeared to be 
the most insensitive algorithm to chl- $a$ concentration, which also confirmed the fact that PC absorption at $600 \mathrm{~nm}$ has less influence of chl- $a$ absorption as compared to that at $620 \mathrm{~nm}$. However, the residual errors found in Mishra et al. [5] could be due to the enhanced interference of another water constituent, i.e., the total suspended solids (TSS). More research is needed to quantify the interference of TSS at $600 \mathrm{~nm}$ and isolate the errors observed in Mishra et al. [5].

In addition, we evaluated the performance of all the PC algorithms for two spaceborne hyperspectral sensors and the upcoming HyspIRI sensor using simulated in situ hyperspectral data. From the analysis, it has been concluded that the three sensors can potentially be used to quantify and map PC concentration using some of the reflectance based algorithms considered in this study. However, CHRIS bands appeared to be more sensitive to chl- $a$ due to its narrow bandwidth around the chl- $a$ reflectance peak. Variations in the bandwidth proved to be a determinant for the accuracy of bio-optical models. Overall, results demonstrate that reflectance based algorithms can be applied to infer PC concentrations and distributions accurately using any of the three sensors.

One of the unique factors of this review paper is the datasets used in comparing the performance of various models. The datasets represent two significantly different waters in terms of their bio-optical properties, one acquired from a tropical reservoir representing oligotrophic conditions and the other from catfish ponds representing hyper-eutrophic conditions. Performance evaluation of PC detection algorithms in a tropical reservoir has not been done previously, demonstrating the presence of a research gap for low latitude areas. For example, Matthew and Bernard [38] stressed the importance of studying lower latitudes by advising future studies to focus on water types in different low latitude geographical regions of the world, mainly where data are lacking. Therefore, inclusion of a dataset from a tropical reservoir in our analysis created a significant difference in the two datasets which allowed us to test the performance and sensitivity of the reflectance based models at very low and very high PC and chl- $a$ presence. We summarize that the influence of chl- $a$ absorption determines the performance of a reflectance based PC prediction model, and that interference is higher at the PC absorption maxima near $620 \mathrm{~nm}$ than at $600 \mathrm{~nm}$. Therefore, Mishra et al. [5] algorithm, which uses a band near $600 \mathrm{~nm}$, showed the highest overall PC prediction accuracy. We conclude that for comprehensive water quality monitoring including accurate prediction of cyanobacteria content in water, a band at $600 \mathrm{~nm}$ is imperative in future multispectral and hyperspectral sensors.

\section{Acknowledgments}

We thank the Remote Sensing Graduate Program at the National Institute for Space Research (INPE) for funding part of the field trip and grant 2011/19523-8, São Paulo Research Foundation (FAPESP) for funding part of the field trip. Igor Ogashawara also thanks the Coordination for the Improvement of Higher Education Personnel (CAPES) for the scholarship grant. Special thanks to the University of Georgia for providing funds and facilitating the collaboration between the INPE and UGA through the international student internship program.

\section{Conflicts of Interest}

The authors declare no conflict of interest. 


\section{References}

1. Sun, D.; Li, Y.; Wang, Q.; Gao, J.; Le, C.; Huang, C.; Gong, S. Hyperspectral Remote Sensing of the Pigment C-Phycocyanin in Turbid Inland Waters, Based on Optical Classification. IEEE Trans. Geosci. Remote Sens. 2013, 99, 1-14.

2. Codd, G.A.; Lindsay, J.; Young, F.M.; Morrison, L.F.; Metcalf, J.S. Harmful Cyanobacteria. In Harmful Cyanobacteria, 1st ed.; Huisman, J., Matthijs, H.C.P., Visser, P.M., Eds.; Springer: Dordrecht, The Netherlands, 2005; Chapter 1, pp. 1-23.

3. Sivonen, K.; Jones, G. Cyanobacterial Toxins. In Toxic Cyanobacteria in Water: A Guide to Their Public Health Consequences, Monitoring and Management, 1st ed.; Chorus, I., Bartram, J., Eds.; UNESCO/WHO/UNEP: London, UK, 1999; Chapter 3, pp. 55-124.

4. Azevedo, S.M.F.O.; Carmichael, W.W.; Jochimsen, E.M.; Rinehart, K.L.; Lau, S.; Shaw, G.R.; Eaglesham, G.K. Human intoxication by microcystins during renal dialysis treatment in Caruaru-Brazil. Toxicology 2002, 181-182, 441-446.

5. Mishra, S.; Mishra, D.R.; Schluchter, W.M. A novel algorithm for predicting phycocyanin concentrations in cyanobacteria: A proximal hyperspectral remote sensing approach. Remote Sens. 2009, 1, 758-775.

6. Reynolds, C.S. Ecology of Phytoplankton, 1st ed.; Cambridge University Press: Cambridge, UK, 2006; p. 535.

7. Shapiro, J. Current beliefs regarding dominance by blue-greens: the case for the importance of CO2 and pH. Verh. Int. Ver. Limnol. 1990, 24, 38-54.

8. El-Alem, A.; Chokmani, K.; Laurion, I.; El-Adlouni, S.E. Comparative analysis of four models to estimate chlorophyll-a concentration in Case-2 waters using moderate resolution imaging spectroradiometer (MODIS) imagery. Remote Sens. 2012, 4, 2373-2400.

9. Le, C.; Li, Y.; Zha, Y.; Wang, Q.; Zhang, H.; Yin, B. Remote sensing of phycocyanin pigment in highly turbid inland waters in Lake Taihu, China. Int. J. Remote Sens. 2011, 32, 8253-8269.

10. Simis, S.G.H.; Peters, S.W.M.; Gons, H.J. Remote sensing of the cyanobacterial pigment phycocyanin in turbid inland water. Limnol. Oceanogr. 2005, 50, 237-245.

11. Hunter, P.D.; Tyler, A.N.; Carvalho, L.; Codd, G.A.; Maberly, S.C. Hyperspectral remote sensing of cyanobacterial pigments as indicators for cell populations and toxins in eutrophic lakes. Remote Sens. Environ. 2010, 114, 2705-2718.

12. Mishra, S.; Mishra, D.R.; Lee, Z.; Tucker, C.S. Quantifying cyanobacterial phycocyanin concentration in turbid productive waters: A quasi-analytical approach. Remote Sens. Environ. 2013, 133, 141-151.

13. Reinart, A.; Kutser, T. Comparison of different satellite sensors in detecting cyanobacterial bloom events in the Baltic Sea. Remote Sens. Environ. 2006, 102, 74-85.

14. Hunter, P.D.; Tyler, A.N.; Gilvear, D.J.; Willby, N.J. Using remote sensing to aid the assessment of human health risks from blooms of potentially toxic cyanobacteria. Environ. Sci. Technol. 2009, 43, 2627-2633.

15. Randolph, K.; Wilson, J.; Tedesco, L.; Li, L.; Pascual, D.P.; Soyeux, E. Hyperspectral remote sensing of cyanobacteria in turbid productive water using optically active pigments, chlorophyll a and phycocyanin. Remote Sens. Environ. 2008, 112, 4009-4019. 
16. Dekker, A.G. Detection of Optical Water Quality Parameters for Eutrophic Waters by High Resolution Remote Sensing. Ph.D. Thesis, Vrije Universiteit, Amsterdam, The Netherlands, 1993.

17. Schalles, J.F.; Yacobi, Y.Z. Remote detection and seasonal patterns of phycocyanin, carotenoid, and chlorophyll pigments in eutrophic waters. Archives Hydrobiologica 2000, 55, 153-168.

18. Branco, C.W.C.; Rocha, M.I.A.; Pinto, G.F.S.; Gômara, G.A.; De Filippo, R. Limnological features of Funil Reservoir (R.J., Brazil) and indicator properties of rotifers and cladocerans of the zooplankton community. Lakes Reservoirs: Res. Manage. 2002, 7, 87-92.

19. Rocha, M.I.A.; Branco, C.W.C.; Sampaio, G.F.; Gômara, G.A.; De Filippo, R. Spatial and temporal variation of limnological features, Microcystis aeruginosa and zooplankton in a eutrophic reservoir (Funil Reservoir, Rio de Janeiro). Acta Limnol. Brasil. 2002, 14, 73-86.

20. Tucker, C.S. Ecology of channel catfish culture ponds in northwest Mississippi. Rev. Fisheries Sci. 1996, 4, 1-54.

21. Mobley, C.D. Estimation of the remote-sensing reflectance from above-surface measurements. Appl. Optics 1999, 38, 7442-7455.

22. Ohde, T.; Siegel, H. Derivation of immersion factors for the hyperspectral TriOS radiance sensor. J. Optics A: Pure Appl. Optics 2003, 5, L12-L14.

23. Austin, R.W.; Halikas, G. The Index of Refraction of Seawater; Visibility Laboratory-Scripps Institute of Oceanography: La Jolla, CA, USA, 1976.

24. Nush, E.A. Comparison of different methods for chlorophyll and phaeopigment determination. Arch. Hydrobiol. Beih. Ergebn. Limnol. 1980, 14, 14-36.

25. Lorenzen, C.J. Determination of chlorophyll and pheo-pigments: Spectrophotometric equations. Limnol. Oceanogr. 1967, 12, 343-346.

26. Arar, E.J. Determination of Chlorophylls $a$ and $b$ and Identification of Other Pigments of Interest in Marine and Freshwater Algae Using High Performance Liquid Chromatography with Visible Wavelength Detection. In USEPA Method 447-0; US Environmental Protection Agency: Cincinnati, OH, USA, 1997.

27. Sarada, R.; Pillai, M.G.; Ravishanker, G.A. Phycocyanin from Spirulina sp: Influence of processing of biomass on phycocyanin yield, analysis of efficacy of extraction methods and stability studies on phycocyanin. Process. Biochem. 1999, 34, 795-801.

28. Bennett, A.; Bogorad, L. Complementary chromatic adaptation in a filamentous blue-green alga. J. Cell. Biol. 1973, 58, 419-435.

29. Mishra, S. Remote Sensing of Harmful Algal Bloom. Ph.D. Thesis, Mississippi State University, Mississippi State, MS, USA, 2012.

30. Vincent, R.K.; Qin, X.M.; McKay, R.M.L.; Miner, J.; Czajkowski, K.; Savino, J.; Bridgeman, T. Phycocyanin detection from LANDSAT TM data for mapping cyanobacterial blooms in Lake Erie. Remote Sens. Environ. 2004, 89, 381-392.

31. Dall'Olmo, G.; Gitelson, A.A. Effect of bio-optical parameter variability on the remote estimation of chlorophyll-a concentration in turbid productive waters: experimental results. Appl. Optics 2005, 44, 412-422.

32. Post, A.F.; Wit, R.; Mur, L.R. Interactions between temperature and light intensity on growth and photosynthesis of the cyanobacterium Oscillatoria agardhii. J. Plankton Res. 1985, 7, 487-495. 
33. Gitelson, A. Non-destructive Estimation of Foliar Pigment (chlorophylls, carotenoids, and anthocyanins) Contents: Evaluating a Semi-analytical Three-band Model. In Hyperspectral. Remote Sensing of Vegetation; Thenkabail, P.S., Lyon, G.J., Huete, A., Eds.; CRC Press-Taylor and Francis Group: Boca Raton, FL, USA, 2011; pp. 141-166.

34. Mariotto, I.; Thenkabail, P.S.; Huete, A.; Slonecker, E.T.; Platonov, A. Hyperspectral versus multispectral crop-productivity modeling and type discrimination for the HyspIRI mission. Remote Sens. Environ. 2013, 139, 291-305.

35. Cutter, M.A.; Lobb, D.R.; Williams, T.L.; Renton, R.E. Integration \& Testing of the Compact High-Resolution Imaging Spectrometer (CHRIS). Proc. SPIE 1999; 3753, pp.180-191.

36. Barry, P.S.; Mendenhall, J.; Jarecke, P.; Folkman, M.; Pearlman, J.; Markham, B. EO-1 Hyperion Hyperspectral Aggregation and Comparison with EO-1 Advanced Land Imager and Landsat 7 ETM+. In Proceedings of 2002 International IEEE Geoscience and Remote Sensing Symposium, Toronto, ON, Canada, 24-28 June 2002; pp. 1648-1651.

37. Kutser, T. Quantitative detection of chlorophyll in cyanobacterial blooms by satellite remote sensing. Limnol. Oceanogr. 2004, 49, 2179-2189.

38. Matthews, M.W.; Bernard, S. Similar studies should be performed in diverse inland waters representative of other geographical regions of the world where data are lacking. Remote Sens. 2013, 5, 4370-4404.

(C) 2013 by the authors; licensee MDPI, Basel, Switzerland. This article is an open access article distributed under the terms and conditions of the Creative Commons Attribution license (http://creativecommons.org/licenses/by/3.0/). 